\title{
Espécies vegetais como recurso terapêutico na Chapada do Araripe no Estado do
}

\section{Ceará, Nordeste do Brasil}

Plant species as a therapeutic resource in Chapada do Araripe in the State of Ceará, Northeastern Brazil

Especies vegetales como recurso terapéutico en Chapada do Araripe en el Estado de Ceará, Noreste de Brasil

Francisco Sydney Henrique da Silva ORCID: https://orcid.org/0000-0002-4771-6570 Universidade Estadual do Ceará, Brasil

E-mail: sidneyhenrique.08@hotmail.com

Saulo Leite de Paula

ORCID: https://orcid.org/0000-0002-9511-6115 Universidade Estadual do Ceará, Brasil E-mail: saulolp@yahoo.com.br

Bárbara Virgínia da Silva Souza ORCID: https://orcid.org/0000-0002-3925-6973 Centro Universitário Católica de Quixadá, Brasil E-mail: barbaravirginiaasz@gmail.com

Marcio Pereira do Nascimento ORCID: https://orcid.org/0000-0001-5838-4818 Universidade Regional do Cariri, Brasil E-mail: marcio.nascimento@urca.br Niwiarakelly da Silva Monte

ORCID: https://orcid.org/0000-0001-6801-2591 Universidade Regional do Cariri, Brasil E-mail: niwiarakellybio@gmail.com

Cícero Jorge Verçosa

ORCID: https://orcid.org/0000-0002-3284-6719 Secretaria de Educação e Esportes de Pernambuco, Brasil E-mail: cjvercosa@hotmail.com

Priscilla Augusta de Sousa Fernandes ORCID: https://orcid.org/0000-0001-7357-1013 Universidade Regional do Cariri, Brasil E-mail: prisciasf@gmail.com

Allyson Francisco dos Santos ORCID: https://orcid.org/0000-0001-8635-6398 Secretaria de Educação e Esportes de Pernambuco, Brasil

E-mail: allysons@outlook.com.br

Antônio Carlito Bezerra dos Santos ORCID: https://orcid.org/0000-0002-2095-5512 Universidade Regional do Cariri, Brasil E-mail: carlito.santos@urca.br 


\begin{abstract}
Resumo
O objetivo desse trabalho foi investigar o conhecimento da comunidade do Sítio Pinheira no município de Missão VelhaCE acerca das plantas medicinais, bem como, a parte usada e a forma de utilização. Foram realizadas entrevistas semiestruturadas com moradores com idade variando entre 60 a 88 anos, correspondendo a 44 pessoas de ambos os sexos. As perguntas foram baseadas em questões pessoais e conhecimento etnobotânico. As espécies foram identificadas através de registros fotográficos feitos no momento das entrevistas, sendo as fotografias comparadas com bibliografia especializada e os nomes científicos confirmados no banco de dados virtual Flora do Brasil 2020. Obteve-se um total de 148 espécies medicinais, distribuídas em 65 famílias botânicas, tendo maior destaque Asteraceae, Fabaceae e Lamiaceae. Como parte mais utilizada obteve-se a folha como $40 \%$ das respostas, a forma mais usada para o tratamento foi o método da decocção com $36 \%$ das citações. As doenças mais referidas foram as relacionadas ao sistema respiratório e ao sistema digestório. Conclui-se que a comunidade faz um grande uso de plantas medicinais e que pode ser considerada uma comunidade tradicional.
\end{abstract}

Palavras-chave: Plantas medicinais; Conhecimento tradicional; Tratamento de doenças.

\begin{abstract}
The objective of this work was to investigate the knowledge of the community of Sítio Pinheira in the municipality of Missão Velha-CE about medicinal plants, as well as the part used and the form of use. Semi-structured interviews were conducted with residents ranging in age from 60 to 88 years, corresponding to 44 people of both sexes. The questions were based on personal issues and ethnobotanical knowledge. The species were identified through photographic records made at the time of the interviews, the photographs being compared with specialized bibliography and the scientific names confirmed in the Flora do Brasil 2020 virtual database. A total of 148 medicinal species were obtained, distributed in 65 families botanical, with greater emphasis on Asteraceae, Fabaceae and Lamiaceae. As the most used part, the sheet was obtained as $40 \%$ of the answers, the most used form for the treatment was the decoction method with $36 \%$ of the citations. The most referred diseases were those related to the respiratory system and the digestive system. It is concluded that the community makes a great use of medicinal plants and that it can be considered a traditional community.
\end{abstract}

Keywords: Medicinal plants; Traditional knowledge; Disease treatment.

\title{
Resumen
}

El objetivo de este trabajo fue investigar el conocimiento de la comunidad de Sítio Pinheira en la ciudad de Missão Velha-CE sobre las plantas medicinales, así como la parte utilizada y la forma de uso. Se realizaron entrevistas semiestructuradas a residentes con edades comprendidas entre 60 y 88 años, correspondientes a 44 personas de ambos sexos. Las preguntas se basaron en cuestiones personales y conocimientos etnobotánicos. Las especies fueron identificadas mediante registros fotográficos realizados al momento de las entrevistas, y las fotografías fueron comparadas con bibliografía especializada y los nombres científicos confirmados en la base de datos virtual Flora do Brasil 2020. Se obtuvieron un total de 148 especies medicinales, distribuidas en 65 familias. botánicos, con mayor énfasis en Asteraceae, Fabaceae y Lamiaceae. Como parte más utilizada, la hoja se obtuvo como el $40 \%$ de las respuestas, la forma más utilizada para el tratamiento fue el método de decocción con el $36 \%$ de las citas. Las enfermedades más reportadas fueron las relacionadas con el aparato respiratorio y el aparato digestivo. Se concluye que la comunidad hace un gran uso de las plantas medicinales y que puede considerarse una comunidad tradicional.

Palabras clave: Plantas medicinales; Conocimientos tradicionales; Tratamiento de enfermedades.

\section{Introdução}

Desde tempos remotos, as plantas eram usadas para fins de diagnóstico, profilaxia ou cura, usos esses que se perpetuaram na história (Souza et al., 2016). Dessa forma, Amorozo e Gély (1988) definiram planta medicinal como aquela que tem valor de cunho curativo.

As plantas medicinais utilizadas em comunidades tradicionais como remédios caseiros, hoje são consideradas matériaprima para fabricação de fitoterápicos e outros medicamentos (Leão, Ferreira e Jardim, 2007). Por isso, desde cedo ouvimos relatos de utilização de plantas medicinais e esse conhecimento tem passado de geração a geração, onde os mais idosos tendem a transmitir esse conhecimento aos filhos e netos, constituindo assim, parte da cultura de um povo (Melro et al., 2019; Silva et al., 2021).

Historicamente, o uso de plantas faz parte da vida da humanidade. O homem, para ampliar seu conhecimento, usou desde a sua pré-história, a intuição e analogia, fazendo assim, um caminho sábio para descobrir a utilidade de cada planta. O uso das espécies vegetais com fins de tratamento e cura de doenças, aparece desde o início da civilização, onde o homem despertou 
para um longo percurso de manuseio dos recursos naturais em seu próprio benefício (Di Stasi, 1996).

Os grupos humanos que vivem na área rural recebem como herança cultural a utilização de plantas medicinais, as alegações de uso e as formas de preparo e administração (Pinto, 2008). Caso a ingestão da planta pudesse causar efeitos tóxicos, a população não a utilizaria mais como medicinal e passaria a identificá-la como uma planta tóxica. No conhecimento tradicional, se diferencia uma planta tóxica de uma medicinal pela observação dos sintomas que a planta produz sobre o organismo (Coan e Matias, 2014). Assim, as que serviam para alguma utilidade poderiam ser compartilhadas entre familiares e vizinhos e as que fossem consideradas como tóxicas poderiam servir de alerta para não se utilizar.

No final do séc. XIX, com o advento da Revolução Industrial, o poder curativo das ervas passou a ser ridicularizado, a ser considerado ultrapassado (Silva Prim, s. d.). De acordo com França et al. (2008) e Veiga (2008), houve um maior enfoque no tratamento alopático. A partir de maio de 1978, segundo resolução estabelecida pela ONU, foi recomendado a todos os países do mundo o estudo científico de plantas medicinais em uso pela medicina popular. Tal recomendação foi feita como forma de permitir a identificação de agentes terapêuticos para a produção, manipulação e tratamento de saúde da população em regiões desprovidas ou ineficientes em assistência à saúde, ou ainda, onde houver uma concentração de pessoas de baixa renda (Almeida et al., 2012).

A pesquisa etnobotânica cresceu visivelmente na última década em muitas partes do mundo, em especial na América Latina, e particularmente em países como o México, a Colômbia e o Brasil (Hamilton et al. 2003).

No Brasil, o uso intenso de plantas medicinais se deve, principalmente, à riqueza e variedade de espécies da flora nativa (Santos et al., 2018). Portanto, os estudos etnobotânicos são fundamentais, pois ao se dedicar ao estudo das interações entre populações humanas e plantas, identifica-se o que pensam as populações a respeito do uso das plantas medicinais, o nível de conhecimento que possuem e quais são os tratamentos feitos com os remédios caseiros (Coan \& Matias, 2014). Para Silva et al. (2016), o conhecimento tradicional deve ser valorizado, pois este também pode servir para uma forma de uso consciente desses vegetais.

De acordo com Albuquerque e Andrade (2002), em uma pesquisa realizada no bioma Caatinga, retrataram que o mesmo está muitas vezes relacionado com a ideia de improdutividade, porém na região de Alagoinha/PE onde foi realizado o estudo, constatou-se que a população utilizava e/ou identificavam 108 espécies de plantas, dentre elas, estava a categoria das medicinais, com o total de 57. Ribeiro et al. (2014) realizavam uma pesquisa no distrito de Aratama, município de Assaré/CE, onde foram observadas a utilização de 116 espécies medicinais. Já Silva et al. (2015) afirmaram em seus resultados no Sítio Nazaré, município de Milagres/CE, um registro de 62 espécies medicinais.

Assim sendo, estes saberes tornam-se cada vez mais reliquiais e persistem quase exclusivamente nas pessoas mais antigas. Deste modo, estes saberes tradicionais, que são parte integrante do patrimônio cultural de um povo, tendem a desaparecer com o tempo ou mesmo a extinguir-se a médio prazo, caso nada se faça para o impedir (Rodrigues et al., 2007). De acordo com Albuquerque e Andrade (2002), esse conhecimento acumulado pode servir como uma forma que desenvolvimentistas e conservacionistas tem para planejamento e manutenção das áreas.

Analisando todos esses aspectos, somando-se a falta de pesquisas sobre o assunto no local em questão, se faz necessário um estudo acerca da utilização de plantas medicinais pela população do Sítio Pinheira no município de Missão Velha no Ceará. Assim, objetivou-se com este trabalho contribuir para a pesquisa etnobotânica na comunidade supracitado, bem como, estimular futuras pesquisas e servir de referência para estudos posteriores. 


\section{Metodologia}

\section{1 Área de estudo}

A pesquisa foi realizada no Sítio Pinheira, uma pequena comunidade onde a atividade econômica principal é a agricultura. Está localizada entre as coordenadas geográficas -7.417583, -39.128871 e -7.426891, -39.127369 (Google EarthMapas, 2018) e dista dois quilômetros do distrito de Jamacaru, 22 quilômetros do município sede de Missão Velha, no estado do Ceará e a $60 \mathrm{~km}$ da Floresta Nacional do Araripe - Apodi (FLONA). Possui temperaturas que podem chegar a menos de $20^{\circ} \mathrm{C}$, uma vez que está localizada no Sopé da Chapada do Araripe, é uma região rica em fontes de água e muito conhecida pela presença de fósseis (Figura 1).

O município de Missão Velha dispõe de uma área de $645,7 \mathrm{Km}^{2}$, possui clima Tropical Quente Semiárido, sua vegetação é compreendida por Floresta Caducifólia Espinhosa, Floresta Subcaducifólia Tropical Pluvial, Floresta Subcaducifólia Tropical Xeromorfa e Floresta Subperenifólia Tropical Pluvio-Nebular (IPECE, 2016).

Figura 1: Mapa de localização geográfica da Floresta Nacional do Araripe- Apodi e do município de Missão Velha, Ceará, Brasil.

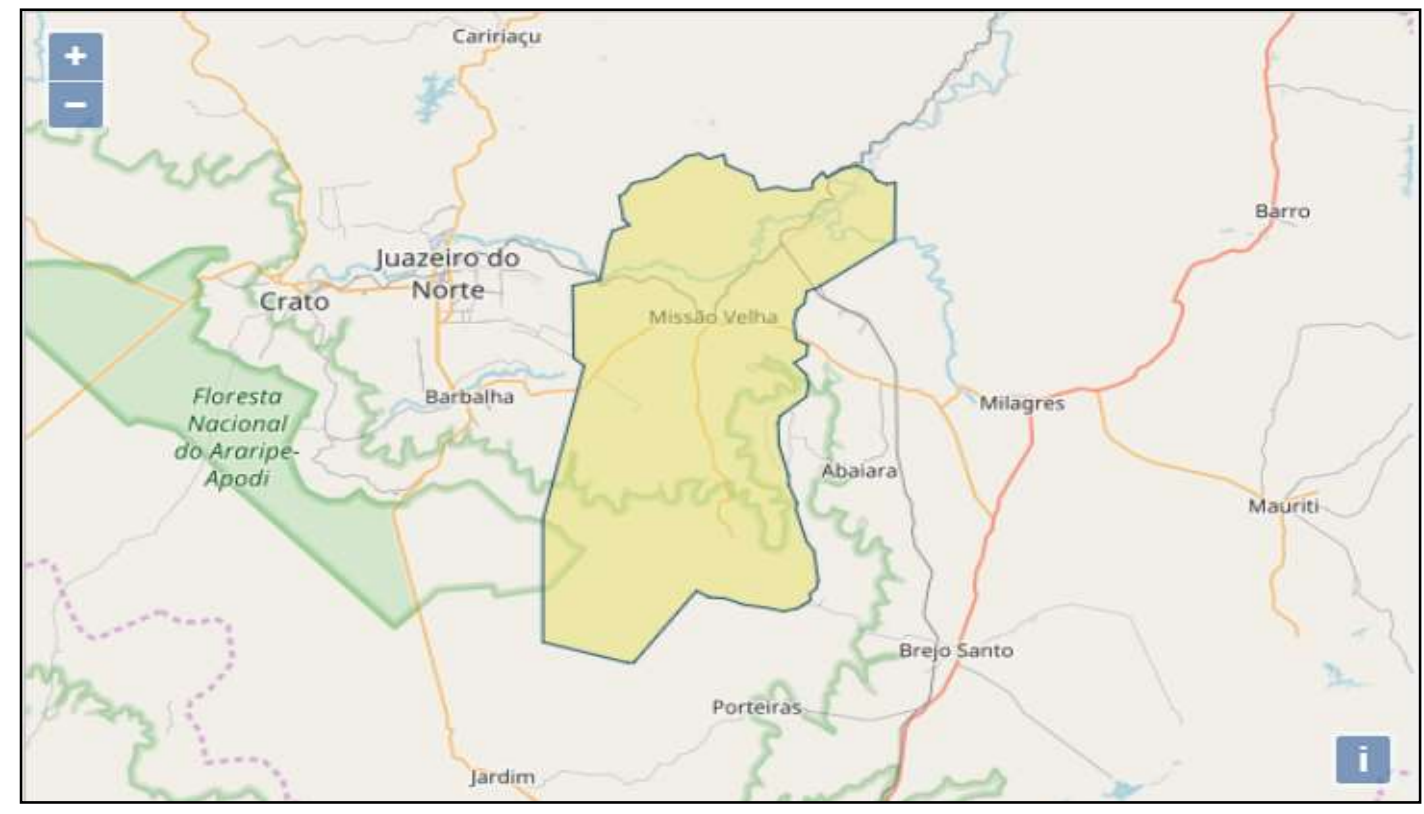

Fonte: Instituto Brasileiro de Geografia e Estatística (2018).

A comunidade do Sítio Pinheira possui aproximadamente 710 habitantes, dispondo de energia elétrica, água encanada, uma escola de Ensino Fundamental I e uma creche. Conta ainda com três mercantis, um posto de saúde, uma capela e uma igreja evangélica. É conhecida por ser uma sociedade ainda sustentada em parte pela agricultura familiar, onde uma grande parcela da população possui um rico conhecimento acerca das plantas medicinais, podendo ser assim, designada por comunidade tradicional.

\subsection{Obtenção dos dados}

Inicialmente foi analisada a população conhecedora de plantas medicinais com o auxílio da agente de saúde da comunidade, a qual auxiliou prestando informações referentes as idades dos possíveis participantes, bem como, ajudando a listar os que não teriam mais possibilidades de responder conscientemente.

O trabalho foi realizado no período de Julho a Setembro de 2017, o qual constou com entrevista semiestruturada, 
contendo dados pessoais e o conhecimento etnobotânico, como por exemplo, o uso, a coleta, a finalidade e o modo de preparo de cada planta que o entrevistado utilizava. $\mathrm{Na}$ oportunidade era solicitado que indicasse todas as espécies medicinais que conheciam, bem como, sua parte utilizada, forma de uso e indicação. A origem das plantas no quesito de ser ou não nativa foi pesquisada no banco de dados virtual do REFLORA 2020, como também em bibliografias especializadas.

A amostra da população consistiu em pessoas com mais de 60 anos, já que as pessoas mais idosas são as detentoras de maior conhecimento sobre as plantas medicinais, conforme afirma por Neto et al. (2014). A técnica usada foi "amostragem em Bola de Neve", "Bola de Neve" ou "cadeia de informantes" (Penrod et al., 2003), na qual um entrevistado sugeria alguém que ele conhecesse e que fosse detentor de conhecimento sobre o tema em questão.

As entrevistas foram realizadas através de visitas nas residências dos entrevistados. $\mathrm{O}$ tempo gasto em cada entrevista variou conforme o conhecimento de cada entrevistado, variando entre 20 minutos a 1 hora e 30 minutos.

Inicialmente foi lido o Termo de Consentimento Livre Esclarecido e após o entendimento do entrevistando, sua aceitação e assinatura do mesmo, iniciava-se a entrevista. Após as entrevistas foram fotografadas as espécies citadas pelos entrevistados, essa metodologia também foi utilizada no trabalho de Salgado e Guido (2008), no distrito de Martinésia, Uberlândia - MG. A identificação botânica ocorreu baseada nas fotografias e por comparação com material bibliográfico especializado. A grafia dos nomes científicos, bem como dos autores foram corrigidos e/ou confirmados no banco de dados virtual do REFLORA 2020 (http://reflora.jbrj.gov.br/reflora/listaBrasil/ConsultaPublicaUC/ResultadoDaC onsultaNovaConsulta.do\#CondicaoTaxonCP).

\section{Resultados e Discussão}

Foram entrevistados um total de 44 moradores, sendo 60\% (26) do sexo feminino e $40 \%$ (18) do sexo masculino, com faixa etária variando entre 60 a 88 anos (Tabela 1). De acordo com Borba e Macêdo (2006), as mulheres detêm de maior conhecimento etnobotânico e principalmente se as espécies utilizadas forem próximas de casa, já Amorozo e Gély (1988) afirmam que os homens tendem a conhecer mais as plantas de mato.

Tabela 1: Idades e sexo dos entrevistados da comunidade do Sítio Pinheira no município de Missão Velha, Ceará, Brasil.

\begin{tabular}{lcccc}
\hline & \multicolumn{3}{c}{ IDADES } & TOTAL \\
\hline SEXO & 60 a 70 anos & 71 a 80 anos & 81 a 88 anos \\
Feminino & 14 & 09 & 03 & 26 \\
Masculino & 12 & 03 & 03 & 18 \\
TOTAL & 26 & 12 & 06 & 44 \\
\hline
\end{tabular}

Fonte: Autores (2018).

No questionamento a respeito do uso de cigarro ou álcool apenas três informaram que são fumantes e dois que faziam uso de álcool. Dos fumantes, um deles citou o cansaço como um problema ocasionado pelo hábito de fumar e que para amenizar esse problema utilizava-se do chá da planta Mentha x villosa Huds.

A respeito do nível de escolaridade, a maioria (70,45\%) afirmou que não completaram o Ensino Fundamental I e apenas dois com Ensino Médio completo (Figura 2). Os conhecimentos provenientes de gerações anteriores devem ser conservados, entretanto, é importante ressaltar que as pessoas que têm este conhecimento são aquelas com idade superior a 60 anos e nível de escolaridade mais baixo, ao passo que as pessoas mais jovens e com melhor nível de escolaridade se mostram pouco interessadas na fitoterapia (Balbinot, Velasquez \& Düsman, 2013). 
Figura 2: Nível de escolaridade dos entrevistados da comunidade do Sítio Pinheira no município de Missão Velha, Ceará, Brasil.

\section{Escolaridade}

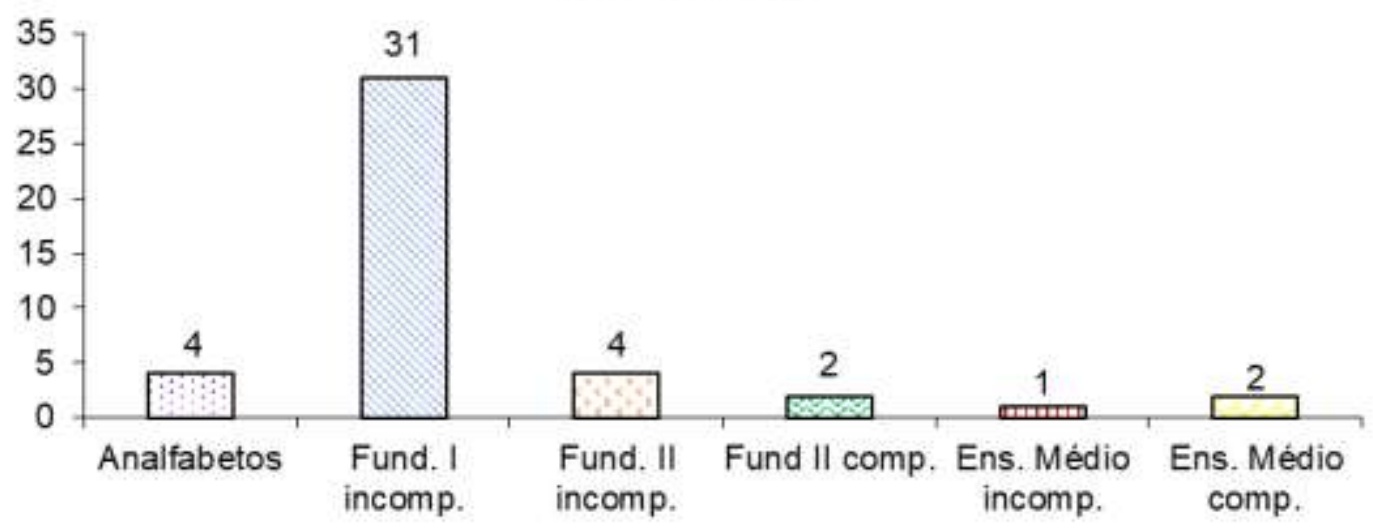

Fonte: Autores (2018).

No que se diz respeito à profissão, 23 são aposentados e 21 agricultores, dentre esses últimos, alguns também eram aposentados, mas afirmaram que trabalham para complementar a renda ou por não querer parar de trabalhar na roça.

Do total de entrevistados, 68\% (30) são naturais do Sítio Pinheira ou moram por mais de 30 anos na localidade, 22,8\% (10) moram no Sítio entre 10 a 20 anos e 9,2\% (4) possuem o tempo de moradia de 21 a 30 anos.

No presente estudo foram encontradas 148 espécies de plantas medicinais, distribuídas em 65 famílias (Tabela 02). As famílias botânicas com a maior representação foram a Asteraceae com 15 espécies, seguido por Fabaceae (14) e Lamiaceae (10). Os resultados corroboram com os encontrados no trabalho de Rodrigues e Andrade (2014), na comunidade de Inhamã-PE, no qual as famílias supracitadas aparecem como as que tem o maior número de espécies. Com relação a origem das plantas com fins medicinais, 50\% (74) delas são exóticas e 50\% (74) nativas.

Com relação à parte utilizada da planta, observou-se que a folha é a parte mais utilizada correspondendo aproximadamente $40 \%$, seguido por raiz $14,7 \%$, semente $13,1 \%$, casca e entrecasca 12,02\% (Figura 3). O resultado foi semelhante ao encontrado por Neto et al. (2014) em uma pesquisa realizada numa comunidade do município de Catu-BA, e Amorozo (2002) em um trabalho feito no município de Santo Antonio do Leverger-MT, onde a folha e a raiz foram as partes mais utilizadas. 
Figura 3: Gráfico demonstrando as partes utilizadas das plantas medicinais indicadas pelos entrevistados da comunidade do Sítio Pinheira no município de Missão Velha, Ceará, Brasil.

Partes utilizadas das plantas medicinais

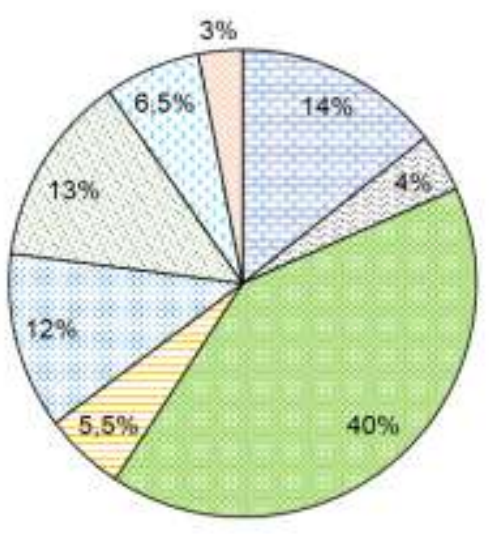

QRaiz

口Caule

口Folha

口Flor

口Casca/ entrecasca

口Semente

口Fruta

口Outros

Fonte: Autores (2018). 
Tabela 2: Lista de espécies medicinais citadas pelos entrevistados do Sítio Pinheira, Jamacaru, Missão Velha- CE, Brasil. Continua...

\begin{tabular}{|c|c|c|c|c|}
\hline Família /Espécie & Nome Popular & Parte Utilizada & Forma de Uso & Indicações \\
\hline Adoxaceae & & & & \\
\hline $\begin{array}{l}\text { Sambucus australis Cham. \& Schltdl. } \\
\text { Alliaceae }\end{array}$ & Flor-de-sabugo & Flor & Decocção & Febre \\
\hline $\begin{array}{l}\text { Allium fistulosum } \mathrm{L} \text {. } \\
\text { Amaranthaceae }\end{array}$ & Cebolinha & Folha & Infusão & Pressão alta \\
\hline $\begin{array}{l}\text { Dysphania ambrosioides (L.) Mosyakin \& } \\
\text { Clemants } \\
\text { Anacardiaceae }\end{array}$ & Mentruz & Folha & $\begin{array}{l}\text { Sumo, maceração, } \\
\text { infusão e banho }\end{array}$ & Machucado, quebradura, tosse, gripe, inflamação e vermes \\
\hline Anacardium occidentale $\mathrm{L}$. & Cajú & Entrecasca & Banho e maceração & Inflamação e cicatrização \\
\hline Mangifera indica $\mathrm{L}$. & Manga & Folha & Decocção e lambedor & Rouquidão e gripe \\
\hline Myracrodruon urundeuva Allemão & Aroeira-mansa & Entrecasca & $\begin{array}{l}\text { Banho, gargarejo e } \\
\text { lambedor }\end{array}$ & Inflamação, problemas no intestino e cicatrização \\
\hline $\begin{array}{l}\text { Spondias mombin } \mathrm{L} \text {. } \\
\text { Annonaceae }\end{array}$ & Seriguela & Folha & Decocção & Desinteria e dor de barriga \\
\hline Annona muricata L. & Graviola & Folha e casca & Infusão & Câncer e diabetes \\
\hline $\begin{array}{l}\text { Annona squamosa } \mathrm{L} . \\
\text { Apiaceae }\end{array}$ & Pinha & Semente & Maceração (óleo) & Piolho \\
\hline Anethum graveolens $\mathrm{L}$ & Endro & Semente & Infusão & Gastura, calmante, pressão alta e cólica \\
\hline Coriandrum sativum $\mathrm{L}$. & Coentro & Folha & In natura & Queimadura \\
\hline $\begin{array}{l}\text { Pimpinella anisum } \mathrm{L} \text {. } \\
\text { Apocynaceae }\end{array}$ & Erva-doce & Semente & Infusão & Calmante, pressão alta, dor de barriga e gastura \\
\hline Catharanthus roseus (L.) G.Don & Boa-noite & Folha & Decocção & Rouquidão \\
\hline Geissospermum laevis (Vell.) Miers. & Pau-pereira & Caule & Maceração & Dor de barriga \\
\hline Hancornia speciosa Gomes & Mangaba & Caule & Látex com água & Úlcera, quebradura, câncer e dor no estômago \\
\hline $\begin{array}{l}\text { Himatanthus drasticus (Mart.) Plumel } \\
\text { Arecaceae }\end{array}$ & Janaguba & Caule & Látex com água & Dor no estômago e quebradura \\
\hline Cocos nucifera $\mathrm{L}$ & Coco & Fruto & Bebe a água & Desidratação, problemas no intestino e problemas nos rins \\
\hline $\begin{array}{l}\text { Syagrus comosa (Mart.) Mart. } \\
\text { Asphodelaceae }\end{array}$ & Catolé & Semente & Bebe água da semente & Olho inflamado \\
\hline $\begin{array}{l}\text { Aloe vera }(\mathrm{L} .) \text { Burm. f. } \\
\text { Asteraceae }\end{array}$ & Babosa & Folha & Maceração & Gastrite, inflamação, cabeça de prego, câncer e cicatrização \\
\hline Acanthospermum hispidum DC. & Espinho-de-cigano & Raiz & Decocção & Tosse e gripe \\
\hline Ageratum conyzoides $\mathrm{L}$. & Mentrasto & Folha & Decocção & Gripe e cólica \\
\hline Artemisia absinthium $\mathrm{L}$ & Lorma & Folha & Decocção & Dor de barriga \\
\hline Artemisia vulgaris $\mathrm{L}$. & Anador & Folha & Decocção & Dor na coluna \\
\hline Bidens pilosa $\mathrm{L}$. & Espinho-de-agulha & Raiz & Decocção & Gripe \\
\hline Calendula officinalis $\mathrm{L}$. & Mal-me-quer & Flor & Decocção & Úlcera e gastrite \\
\hline
\end{tabular}




\begin{tabular}{|c|c|c|c|c|}
\hline Chaptalia nutans (L.) Pol. & Língua-de-vaca & Raiz & Decocção e maceração & Gripe, febre e sarampo \\
\hline Crysanthemum parthenium Pers. & Artemísia & Folha & Decocção & Dor de barriga \\
\hline Egletes viscosa Less. & Marcela & Semente e folha & Decocção e in natura & Dor de barriga e má digestão \\
\hline Galinsoga parviflora Cav. & Picão & Folha & Infusão & Hepatite e problemas nos rins \\
\hline Família /Espécie & Nome Popular & Parte Utilizada & Forma de Uso & Indicações \\
\hline \multicolumn{5}{|l|}{ Asteraceae } \\
\hline Helianthus annus L & Girassol & Semente & Decocção & Trombose e epilepsia \\
\hline Lactuca sativa $\mathrm{L}$. & Alface & Folha & Infusão e in natura & Calmante, problemas no fígado e problemas no intestino \\
\hline Matricaria chamomilla $\mathrm{L}$. & Camomila & Semente & \multirow{2}{*}{$\begin{array}{l}\text { Infusão } \\
\text { Decocção e cigarro com } \\
\text { a folha }\end{array}$} & Calmante e pressão alta \\
\hline Pluchea sagittalis (Lam.) Cabrera & Quitoco & Folha e semente & & Dor de barriga, dor de dente, dor de cabeça e febre \\
\hline $\begin{array}{l}\text { Vernonia condensata } \text { Baker } \\
\text { Bignoniaceae }\end{array}$ & Boldo & Folha & Infusão e sumo & Má digestão, dor de barriga e gastrite \\
\hline $\begin{array}{l}\text { Crescentia cujete } \mathrm{L} . \\
\text { Bixaceae }\end{array}$ & Coité & Folha & Decocção & Problemas no fígado \\
\hline $\begin{array}{l}\text { Bixa orellana } \mathrm{L} . \\
\text { Boraginaceae }\end{array}$ & Urucum & Semente & Decocção e maceração & Dor no corpo, gripe, tosse, rouquidão e machucado \\
\hline Varronia leucocephala (Moric.) J.S.Mill. & Muleque-duro & Entrecasca & Maceração & Cicatrização \\
\hline $\begin{array}{l}\text { Heliotropium elongatum (Lehm.) I. M. } \\
\text { Johnst }\end{array}$ & Crista-de-galo & $\begin{array}{l}\text { Semente, folha, raiz } \\
\text { e flor }\end{array}$ & Decocção e lambedor & $\begin{array}{l}\text { Trombose, dor de cabeça, gripe, epilepsia e problemas } \\
\text { circulatórios }\end{array}$ \\
\hline Brassicaceae & & & & \\
\hline Brassica rapa $\mathrm{L}$. & Mostarda & Semente & Decocção & Trombose, dor no corpo e epilepsia \\
\hline $\begin{array}{l}\text { Nasturtium officinale } \mathrm{R} . \mathrm{Br} \text {. } \\
\text { Cactaceae }\end{array}$ & Agrião & Flor & Infusão & Rouquidão \\
\hline $\begin{array}{l}\text { Cereus jamacaru DC. } \\
\text { Cannaceae }\end{array}$ & Mandacaru & Caule & Decocção & Inchaço \\
\hline $\begin{array}{l}\text { Canna indica } \mathrm{L} . \\
\text { Caricaceae }\end{array}$ & Caninha-da-índia & Folha & Decocção & Câncer, cansaço e pedras nos rins \\
\hline $\begin{array}{l}\text { Carica papaya } \mathrm{L} . \\
\text { Caryocaraceae }\end{array}$ & Mamão & Fruto & In natura & Olhos \\
\hline $\begin{array}{l}\text { Caryocar coriaceum Wittm. } \\
\text { Cleomaceae }\end{array}$ & Pequi & Casca & Óleo & Inchaço, garganta inflamada, cicatrização e tosse \\
\hline $\begin{array}{l}\text { Tarenaya longicarpa Soares Neto \& } \\
\text { Roalson }\end{array}$ & Mussambê & Flor e raiz & Lambedor e decocção & Tosse e gripe \\
\hline Convolvulaceae & & & & \\
\hline Ipomoea batatas (L.) Lam & Batata-doce & Raiz & Decocção e maceração & Afta e gastrite \\
\hline Ipomoea $\mathrm{sp}$ & Salsa & Folha & Banho & Coceira no corpo \\
\hline Operculina macrocarpa (Linn) Urb & Batata-de-purga & Raiz & Decocção & Laxante, afinar sangue, vermes e inflamação \\
\hline
\end{tabular}


Research, Society and Development, v. 10, n. 13, e341101321300, 2021

(CC BY 4.0) | ISSN 2525-3409 | DOI: http://dx.doi.org/10.33448/rsd-v10i13.21300

\begin{tabular}{|c|c|c|c|c|}
\hline Costus spicatus (Jacq.) Sw. & Cana-do-brejo & Folha & Infusão & Dor no corpo e pressão alta \\
\hline $\begin{array}{l}\text { Crassulaceae } \\
\text { Kalanchoe pinnata (Lam.) Pers. } \\
\text { Cucurbitaceae }\end{array}$ & Folha-santa & Folha & Maceração & Inflamação e cabeça de prego \\
\hline $\begin{array}{l}\text { Citrullus lanatus (Thunb.) Matsum. \& } \\
\text { Nakai }\end{array}$ & Melancia & Semente & Maceração & Dor de barriga \\
\hline Cucurbita pepo L. & Abóbora & Folha & Infusão & Queimadura \\
\hline Momordica charantia L. & Melão-do-mato & Ramo & Sumo & Má digestão \\
\hline Família /Espécie & Nome Popular & Parte Utilizada & Forma de Uso & Indicações \\
\hline \multicolumn{5}{|l|}{ Euphorbiaceae } \\
\hline Croton campestris A.St.-Hil. & Velame & Raiz & Decocção & Gripe e asma \\
\hline Croton echioides Baill. & Quebra-faca & Casca & Maceração & Gripe, dor de barriga, sinusite e dor de cabeça \\
\hline Jatropha gossypifolia L. & Pinhão-roxo & Folha & Infusão & Derrame e dor de cabeça \\
\hline Manihot esculenta Crantz & Mandioca & Raíz & Decocção & Desinteria \\
\hline Phyllanthus niruri L. & Quebra-pedra & Raiz e folha & Decocção & Problemas no fígado e pedra nos rins \\
\hline $\begin{array}{l}\text { Ricinus communis } \mathrm{L} \text {. } \\
\text { Fabaceae }\end{array}$ & Mamona & Semente e casca & Óleo & Laxante e inchaço \\
\hline Amburana cearensis (Allemão) A.C.Sm. & Imburana & Folha e entrecasca & Decocção & Gripe, tosse e melhorar a imunidade \\
\hline Anadenanthera colubrina (Vell.) Brenan. & Angico & Folha e entrecasca & $\begin{array}{l}\text { Decocção, banho e } \\
\text { lambedor }\end{array}$ & Infecção, gripe e tosse \\
\hline Bauhinia forficata subsp. forficata Link. & Mororó & Folha & Decocção & Calmante \\
\hline Cajanus cajan (L.) Huth & Andú & Folha & Infusão & Dor de barriga \\
\hline Caesalpinia pyramidalis Tul & Catingueira & Flor e entrecasca & Infusão e maceração & Tosse e verme \\
\hline Copaifera langsdorffii Desf. & Copaíba & Caule & Óleo & Dor reumática \\
\hline Hymenaea courbaril $\mathrm{L}$. & Jatobá & Entrecasca e fruto & Maceração e lambedor & Bronquite, gripe, afinar sangue, tosse e febre \\
\hline Libidibia ferrea (Mart. ex Tul.) L.P.Queiroz & Jucá & Vargem e folha & $\begin{array}{l}\text { Maceração, lambedor e } \\
\text { decocção }\end{array}$ & Gripe e dor de barriga \\
\hline Mimosa sensitiva $\mathrm{L}$. & Malícia & Raiz & Decocção & Rouquidão, dor de barriga e garganta inflamada \\
\hline Myroxylon peruiferum L. f. & Bálsamo & Folha & Infusão & Dor de barriga \\
\hline Pterodon emarginatus Vogel & Sucupira & Entrecasca & Decocção e banho & Reumatismo \\
\hline $\begin{array}{l}\text { Senna obtusifolia (L.) H.S. Irwin \& } \\
\text { Barneby }\end{array}$ & Fedegoso & Raiz e semente & Decocção & Gripe \\
\hline Senna occidentalis (L.) Link & Manjerioba & Casca e raiz & Maceração e decocção & Tosse e asma \\
\hline Tamarindus indica L. & Tamarindo & Fruta & Infusão e maceração & Afinar sangue e gripe \\
\hline
\end{tabular}

\section{Lamiaceae}


Lavandula sp.

Leonurus sibiricus L.

Mentha arvensis L.

Mentha x villosa Huds

Ocimum basilicum $\mathrm{L}$.

Ocimum gratissimum $\mathrm{L}$.

Plectranthus amboinicus (Lour.) Spreng.

Plectranthus barbatus Andrews

$\begin{array}{lll}\begin{array}{l}\text { Alfazema } \\ \text { Cordão-de-São- }\end{array} & \text { Folha } & \text { Infusão } \\ \begin{array}{l}\text { Francisco } \\ \text { Vick }\end{array} & \text { Fruto } & \text { Decocção } \\ \text { Hortelã } & \text { Folha } & \text { Infusão } \\ \text { Manjericão } & \text { Folha } & \text { Infusão } \\ \text { Alfavaca } & \text { Folha e semente } & \text { Sumo e infusão } \\ \text { Malva-do-reino } & \text { Folha, entrecasca e } & \text { Infusão e maceração } \\ \text { Sete-dores } & \text { Folha } & \text { Infusão e lambedor } \\ & \text { Folha } & \text { Infusão e in natura }\end{array}$

\begin{tabular}{|c|c|c|c|c|}
\hline Família /Espécie & Nome Popular & Parte Utilizada & Forma de Uso & Indicações \\
\hline \multicolumn{5}{|l|}{ Lamiaceae } \\
\hline Rosmarinus officinalis L. & Alecrim & Folha & Infusão e maceração & $\begin{array}{l}\text { Dor de barriga, febre, gripe, problemas no intestino, tosse, dor } \\
\text { de cabeça, pressão alta e dor de dente }\end{array}$ \\
\hline $\begin{array}{l}\text { Tetradenia riparia (Hochst.) Codd. } \\
\text { Lauraceae }\end{array}$ & Pluma & Folha & Decocção & Dor de barriga \\
\hline Cinnamomum zeylanicum Blume. & Canela & Casca & Decocção & Calmante \\
\hline $\begin{array}{l}\text { Persea americana Mill. } \\
\text { Liliaceae }\end{array}$ & Abacate & Folha & Decocção & Problemas nos rins e no fígado \\
\hline Allium сера $\mathrm{L}$. & Cebola-branca & Bulbo & Lambedor e maceração & Gripe e tosse \\
\hline $\begin{array}{l}\text { Allium sativum } \mathrm{L} \text {. } \\
\text { Linaceae }\end{array}$ & Alho & Bulbo & In natura e decocção & Tosse e pressão alta \\
\hline $\begin{array}{l}\text { Linum usitatissimum } \mathrm{L} \text {. } \\
\text { Lythraceae }\end{array}$ & Linhaça & Semente & In natura, suco e óleo & Laxante e cabeça de prego \\
\hline $\begin{array}{l}\text { Punica granatum } \mathrm{L} \text {. } \\
\text { Malpighiaceae }\end{array}$ & Romã & Fruta e casca & Decocção e lambedor & Inflamação na garganta, gripe, rouquidão, câncer e gastrite \\
\hline Byrsonima intermedia A. Juss. & Murici & Entrecasca & Banho & Cicatrização \\
\hline $\begin{array}{l}\text { Malpighia emarginata } \mathrm{L} . \\
\text { Malvaceae }\end{array}$ & Acerola & Fruta e folha & Suco e decocção & Cicatrização, inflamação, gripe e melhorar imunidade \\
\hline Gossypium hirsutum L. & Algodão & Semente & Maceração & Cabeça de prego \\
\hline Guazuma ulmifolia Lam. & Mutamba & Caule & Maceração & Desidratação \\
\hline Hibiscus rosa-sinensis $\mathrm{L}$. & Hibisco & Flor & Infusão & Pressão alta e retenção de líquidos \\
\hline $\begin{array}{l}\text { Waltheria albicans Turcz. } \\
\text { Meliaceae }\end{array}$ & Malva-branca & Folha & Infusão & Intoxicação e gripe \\
\hline $\begin{array}{l}\text { Guarea trichilioides } \mathrm{L} \text {. } \\
\text { Menispermaceae }\end{array}$ & Gitó & Casca & Decocção & Reumatismo \\
\hline
\end{tabular}

Dor de barriga

Dor de barriga

\section{Gripe}

Gripe, dor de ouvido, febre, tontura, dor de cabeça, infecção e cansaço

Dor de ouvido, problemas respiratórios, gripe e olho inflamado

Febre, dor de ouvido e olho inflamado

Tosse, gripe e bronquite

Dor de barriga, má digestão, inflamação, dores no corpo e dor de cabeça 
Research, Society and Development, v. 10, n. 13, e341101321300, 2021

(CC BY 4.0) | ISSN 2525-3409 | DOI: http://dx.doi.org/10.33448/rsd-v10i13.21300

Cissampelos sympodialis Eichler.

\section{Moraceae}

Dorstenia brasiliensis Lam.

Ficus enormis Mart. ex Miq.

\section{Musaceae}

Musa x paradisiaca L.

Myristicaceae

Virola surinamensis (Rol. ex Rottb.) Warb. Noz-moscada

\section{Myrtaceae}

Eucalyptus citriodora Hook

Eugenia uniflora L.

Psidium guajava $\mathrm{L}$.

Psidium guineense $\mathrm{Sw}$.

Syzygium aromaticum (L.) Merr. \& L. M.

Perry

Nyctaginaceae

Boerhavia diffusa $\mathrm{L}$

Família /Espécie

Nyctaginaceae

Bougainvillea spectabilis Willd

\section{Olacaceae}

Ximenia americana $\mathrm{L}$.

Olea europaea L.

\section{Orchidaceae}

Arundina graminifolia (Don) Hochr.

Oxalidaceae

Averrhoa carambola L.

Passifloraceae

Passiflora incarnata $\mathrm{L}$.

Passiflora foetida $\mathrm{L}$.

Pedaliaceae

Sesamum indicum L.

Piperaceae

Piper nigrum L.

Piper umbellatum L.

Poaceae

Cymbopogon citratus (DC) Stapf

Zea mays L.

Phytolaccaceae

Jarrinha

Contra-erva

Gameleira

Banana

Eucalipto

Pitanga

Goiaba

Araçá

Pega-pinto

Trepadeira

Ameixa

Oliveira

Rosa-mélia

Carambola

Gegelim

Capeba

Capim-santo
Cravo-da -índia

Raiz

Maceração

Decocção

Decocção

Decocção

Flor e caule

Semente

Folha

Folha

Folha

Folha

Folha, raiz e

semente

Folha e raiz

Parte Utilizada

Forma de Uso

Lambedor e banho

Decocção

Decocção

Decocção

Infusão

Problemas no intestino

Gripe, dentição, quentura e tosse

Diabetes

Cicatrização, gripe, tosse e quebradura

Dor de cabeça e dor de barriga

Gripe, febre e dor de cabeça

Dor de barriga e ameba

Desinteria e desidratação

Pressão alta e dor de barriga

Asma e dor de dente

Afinar sangue e intoxicação

Indicações

Flor

Folha e fruta

Folha

Flor

Folha e fruta

Maracujá-de-estalo

Maracujá-do-mato

Folha

Pimenta-do-reino

Semente

Semente

Raiz

Folha

Cabelo
Lambedor

Decocção e in natura Infusão

Lambedor

Decocção e in natura

Decocção

Decocção e suco

Decocção

Infusão

Infusão e decocção

Decocção

Infusão
Gripe

Infecção e prisão de ventre

Diabetes

Gripe

Diabetes

Rouquidão, gripe e calmante

Calmante e pressão alta

Evitar aborto

Dor de cabeça

Afinar sangue

Dor de barriga, pressão alta, calmante e dor de cabeça Infecção urinária 
Petiveria alliacea $\mathrm{L}$

Plantaginaceae

Scoparia dulcis L.

\section{Rhamnaceae}

Sarcomphalus joazeiro (Mart.)Hauenshild Rubiaceae

Coffea arabica $\mathrm{L}$.

Coutarea hexandra (Jacq). K. Schum.

Genipa americana $\mathrm{L}$.

Morinda citrifolia L.

\section{Rutaceae}

Citrus limon (L.) Burm. f.

Citrus sinensis (L.) Osbeck

Murraya paniculata (L.) Jack

Ruta graveolens $\mathrm{L}$.

\section{Salicaceae}

Casearia sylvestris $\mathrm{Sw}$.

Laetia americana $\mathrm{L}$

Talisia esculenta (Cambess.) Radlk.

Família /Espécie

\section{Sapotaceae}

Sideroxylon obtusifolium (Roem. \& Schult.) T.D.Penn

\section{Selaginaceae}

Selaginella convuluta Spring.

Solanaceae

Brunfelsia hopeana (Hook.) Benth.

Solanum paniculatum $\mathrm{L}$.

Smilacaceae

Smilax japicanga Griseb.

Theaceae

Camellia sinensis (L.) Kuntze

\section{Turneraceae}

Turnera subulata $\mathrm{Sm}$.

Urticaceae
Tipi

Folha e raiz

Folha

Folha

Café

Quina-quina

Jenipapo

Noni

Limão

Laranja

Jasmim-laranja

Arruda

Folha-de-carne

Pau-piranha

Pitomba

Nome Popular

Jericó

Manacá

Jurubeba

Japecanga

Chá-preto

Chanana

Folha

Folha

\section{Folha}

Folha

Raiz

Semente

Folha e flor
Decocção e maceração

Decocção e banho

Gemada

Lambedor e infusão

Decocção e banho

Maceração e banho

Suco (com vinho)

Infusão

Decocção e in natura

Decocção

Maceração e infusão

Parte Utilizada

Decocção

Decocção

Forma de Uso

Folha e entrecasca

Decocção e lambedor

Infusão

Decocção

Maceração

Maceração

Infusão
Dor de cabeça, pressão alta e reumatismo

Intoxicação, olho inflamado, pressão alta, sarampo, alergia, catapora, assadura e dentição

Gripe, tosse, cicatrização e garganta inflamada

Gripe e rouquidão

Dor de cabeça, sinusite, cicatrização, reumatismo e dor no corpo

Desmentidura

Diabetes, dor no corpo, câncer, dor de barriga e inflamação

Gripe e tosse

Calmante, dor de barriga, má digestão, labirintite, tosse, pressão alta e gripe

Má digestão e dor de barriga

Dor de ouvido, cólica, dor no corpo, gripe e dor de barriga

Dor no estômago

Cólica

Reumatismo

Indicacões

Reumatismo, dor no corpo e quebradura

Febre

Reumatismo

Paralisia e gripe

Cicatrização

Febre, dor de barriga e má digestão 
Research, Society and Development, v. 10, n. 13, e341101321300, 2021

(CC BY 4.0) | ISSN 2525-3409 | DOI: http://dx.doi.org/10.33448/rsd-v10i13.21300

Cecropia pachystachya Trécul.

Urtica dioica $\mathrm{L}$

Verbenaceae

Lippia alba (Mill.) Brow.

Violaceae

Hybanthus calceolaria (L.) Oken

Zingiberaceae

Alpinia zerumbet (Pers.) B.L.Burtt \&R.

M.Sm.

Zingiber officinale (Willd.) Roscoe.
Toré

Urtiga

Folha

Raiz

Folha

Raiz

Folha

Colônia

Gengibre

\section{Decocção}

Decocção

Infusão

Decocção

Decocção

Lambedor
Problemas nos rins e no fígado

Dor de dente

Dor de barriga, calmante, dor no estômago, desinteria, pressão alta e abrir apetite

Gripe, dor de dente e tosse

Diabetes

Tosse, garganta inflamada, retenção de líquidos, dor de cabeça e no corpo

Fonte: Autores 
Para Amorozo (2002), as plantas da mesma espécie podem apresentar mais de uma parte com finalidade medicinal, tanto para um mesmo problema como para problemas de saúde diferentes. Pode-se citar como exemplo a espécie Heliotropium elongatum (Lehm.) I. M. Johnst, da qual pode ser utilizada sua semente, folha, raiz e flor para vários tipos de enfermidades, dentre elas, a trombose e a dor de cabeça, ou a Averrhoa carambola L. da qual podem ser usadas as folhas ou os frutos para tratar a diabetes.

Com relação às formas de uso das plantas citadas pelos entrevistados, a decocção foi a mais referida, como aproximadamente $36 \%$ das respostas, seguida por infusão e maceração com $21,2 \%$ e $15,02 \%$ respectivamente (Figura 4). Os resultados foram semelhantes aos encontrados por Pinto, Amorozo e Furlan (2006) em uma comunidade rural de Itacaré-BA.

Figura 4. Gráfico da variedade de formas de uso das plantas medicinais citadas pelos entrevistados da comunidade do Sítio Pinheira no município de Missão Velha, Ceará, Brasil.

\section{Formas de uso das plantas medicinais}

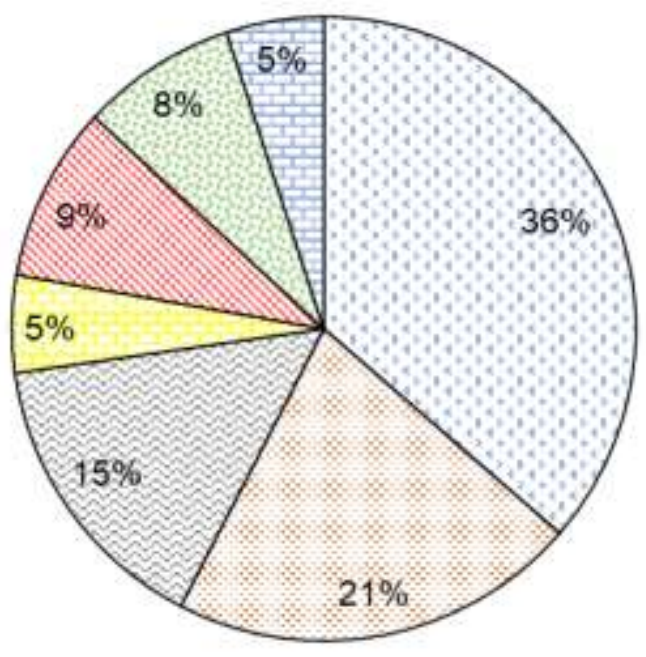

\author{
口Decocção \\ QInfusão \\ 口Maceração \\ 口Banho \\ QOutros \\ 口Lambedor
}

口In natura

Fonte: Autores (2018).

Foram relatadas 68 enfermidades, sendo as que mais tiveram citações foram os problemas ligados ao sistema respiratório, apresentando o percentual de 21,9\% das indicações e ao sistema digestório, tendo 18,5\% das citações totais (Figura 5). Resultados compatíveis com o trabalho de Brito, Marín e Cruz (2017), onde demonstrou com maior destaque nas citações foi o respiratório seguido pelo sistema digestório. 
Figura 5: Enfermidades tratadas através de plantas medicinais referidas pelos entrevistados da comunidade do Sítio Pinheira no município de Missão Velha, Ceará, Brasil.

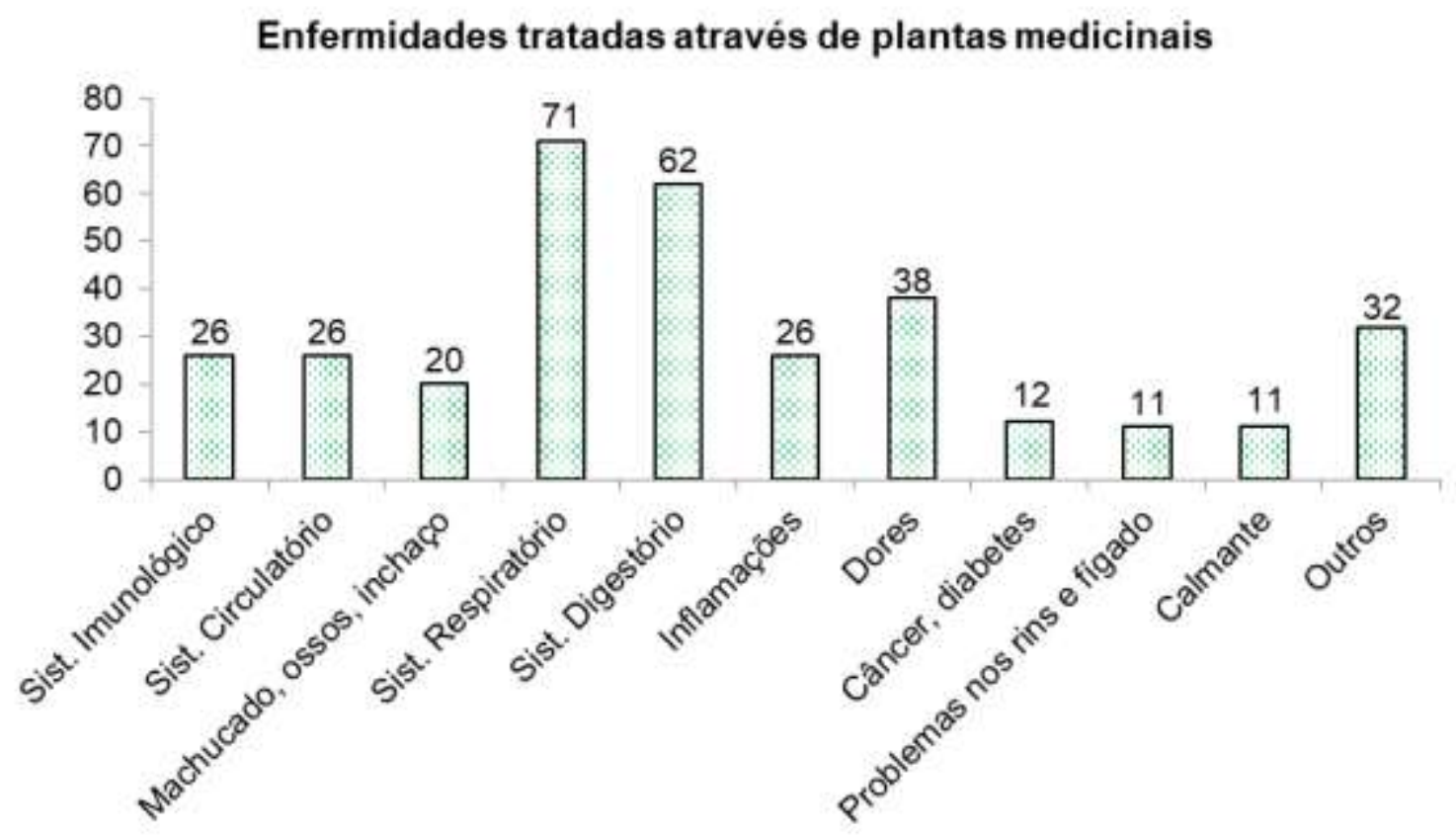

Fonte: Autores (2018).

Isso pode ser apontado como resultado de serem doenças ou problemas mais frequentes como é o caso da gripe, da rouquidão, dor de barriga e má digestão. Os problemas menos citados aparecem no grupo "Outros”, como: cabeça de prego, paralisia e tontura.

As espécies com os maiores números de citações foram Citrus sinensis (L.) Osbeck (laranja), e Plectranthus amboinicus (Lour.) Spreng (malva-do-reino). Santos e Lima (2009), em seu trabalho realizado em Cujubim- RO, também apresentaram as espécies supracitadas como as que estavam entre as mais citadas em seu trabalho. Isso pode ser justificado pelo fato de serem espécies de fácil acesso no local de estudo e por possuírem uma grande versatilidade nas indicações de uso.

Todos os entrevistados responderam que conheciam as plantas medicinais, alguns tinham um pouco mais de conhecimento do que outros, mas todos faziam uso de algum tipo, bem como, acreditavam que elas serviam para a cura de doenças e tinham a preocupação com o cuidado ao meio ambiente. Alguns atribuíram a questão da cura com a fé.

Os quintais, como mostrou no estudo de Morais (2015), são utilizados para cultivar as plantas medicinais, tanto em zonas urbanas, quanto em zonas rurais. Como resposta ao questionamento de como era realizada a coleta da planta, todos os entrevistados cultivavam em seu quintal ao menos uma espécie medicinal e que a coleta era feita retirando apenas o necessário para a utilização. Dentre as espécies que mais tinham nos quintais dos entrevistados destacam-se: Dysphania ambrosioides (L.) Mosyakin \& Clemants, Vernonia condensata Baker. e Lippia alba (Mill.) Brow. Já as espécies mais compradas nos mercantis eram Anethum graveolens L., Pimpinella anisum L., Matricaria chamomilla L. e Cinnamomum zeylanicum Blume.

Alguns entrevistados ainda afirmaram que quando não tinha determinada espécie ao redor de sua residência costumava pedir ao vizinho, havendo assim, uma troca entre espécies que um tinha e o outro não tinha. Resultado parecido pode-se verificar no trabalho de Staniski, Floriani e Strachulski (2014) onde em seu local de estudo as pessoas trocavam plantas medicinais, sem fins comerciais.

No que se diz respeito ao conhecimento acerca das plantas medicinais, os mais representativos foram: 18 citaram os pais como os responsáveis por transmitir esse conhecimento, 14 disseram ser apenas a mãe e apenas quatro ser os avós. Esse 
resultado mostrou que mais de $87 \%$ do conhecimento é transmitido de geração a geração (Figura 6).

Figura 6: Responsável por transmitir o conhecimento sobre as plantas medicinais indicados pelos entrevistados da comunidade do Sítio Pinheira no município de Missão Velha, Ceará, Brasil.

\section{Responsável por transmitir o conhecimento sobre as plantas medicinais}

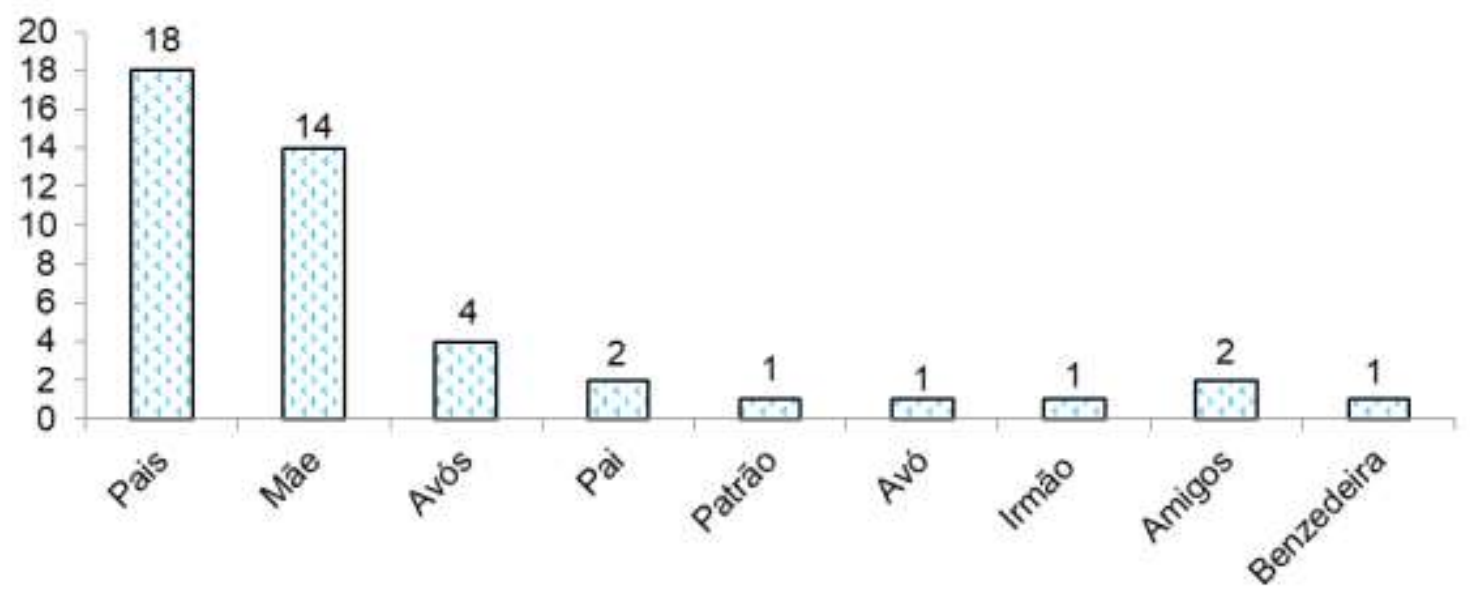

Fonte: Autores (2018).

Os mais jovens não demonstram muito interesse pelo uso das plantas medicinais, podendo isso ser justificado pela facilidade dos medicamentos de farmácias, ou pela pouca vivência com as plantas, sem dar-lhes a devida importância.

No questionamento sobre sentir-se mal devido à utilização de plantas medicinais, apenas dois entrevistados responderam que sim. Um deles relatou que isso ocorreu ao fazer uso do Eucalyptus citriodora Hook., o qual acabou subindo a pressão, já o outro citou a Coutarea hexandra (Jacq). K. Schum. como responsável por uma intoxicação. Esses casos podem ter ocorrido devido a uma dose incorreta ou a administração juntamente com outros medicamentos, o que pode desencadear reações.

De acordo com Arnous, Santos e Beinner (2005), as plantas medicinais tem uma grande importância para a comunidade através das hortas medicinais, possibilitando trocas de informações e aprender uns com os outros. Dessa forma, o conhecimento popular é preservado.

\section{Conclusão}

A pesquisa indicou que a área de estudo apresenta uma variedade de plantas medicinais para o tratamento de uma infinidade de doenças humanas. Revelou ainda, que as pessoas locais preferem medicina popular por serem de baixo custo e às vezes por fazer parte de sua vida social e cultural. É evidente a partir das entrevistas realizadas, que o conhecimento de plantas com fins medicinais é limitado aos idosos que vivem em áreas rurais.

A comunidade do Sítio Pinheira se mostrou também preocupados com o meio ambiente, por retirarem apenas o necessário para o uso medicinal a fim de não danificar a planta. Todos os moradores tem ao menos uma planta no terreiro de casa e demonstram o zelo pelas mesmas.

A maioria dos entrevistados foram do sexo Feminino, com Ensino Fundamental I incompleto e aposentados.

As partes mais utilizadas foram às folhas, o modo de preparo mais citado foi a decocção e as indicações mais referidas foram as relacionadas ao sistema digestório e respiratório.

Os entrevistados relembraram também histórias sobre o uso das plantas quando eram mais novos, falando que 
antigamente as pessoas terminavam dando mais atenção aos ensinamentos dos mais velhos acerca das plantas medicinais, uma vez que, não existia postos de saúde, farmácias ou hospitais próximos e que as doenças tinham de ser curadas através das propriedades medicinais das plantas. Atualmente, com a disponibilidade das farmácias e o fácil acesso aos medicamentos industrializados, as pessoas e principalmente aquelas mais jovens terminam não dando importância para aprender tal conhecimento sobre os vegetais. Concluindo assim que, torna-se necessário adquirir preservar esse sistema da medicina por documentação adequada e identificação de espécimes.

\section{Agradecimentos}

Agradecemos à Universidade Regional do Cariri (URCA).

\section{Referências}

Aguiar, L. C. G. G. \& Barros, R. F. M. (2012). Plantas medicinais cultivadas em quintais de comunidades rurais no domínio do cerrado piauiense (Município de Demerval Lobão, Piauí, Brasil). Revista Brasileira de Plantas Medicinais, 14(3), 419-434.

Albuquerque, U. P. \& Andrade, L. H. C. (2002). Conhecimento botânico tradicional e conservação em uma área de caatinga no estado de Pernambuco, Nordeste do Brasil. Acta Botânica Brasílica, 16(3), 273-285.

Albuquerque, U. P. (2002). Introdução à Etnobotânica. Bagaço. 87p.

Almeida, J. R. G. S. Meira, P. R. M. Nobre, I. B. C. \& Tupiná, J. R. (2012). Uso de plantas medicinais em uma unidade de saúde da família no município de Juazeiro-BA. Revista Interfaces Científicas - Saúde e Ambiente, 1(1), 9-18.

Almeida, M. Z. (2011). Plantas medicinais: abordagem histórico-contemporânea. In: Plantas Medicinais. (3a ed.), EDUFBA, 224p.

Amorozo, M. C. M. \& Gély, A. (1988). Uso de plantas medicinais por caboclos do baixo Amazonas Barcarena, PA, Brasil. Boletim do Museu Paraense Emílio Goeldi, 4(1), 47-131.

Amorozo, M.C.M. (1996). A abordagem etnobotânica na pesquisa de plantas medicinais. In: DI STASI, L.C. Plantas medicinais: arte e ciência. São Paulo: UNESP, 47-68

Amorozo, M. C. M. (2002). Uso e diversidade de plantas medicinais em Santo Antonio do Leverger, MT, Brasil. Acta Botanica Brasílica, 16(2), 189-203.

Araújo, E.C. Araújo, E. C. A. Coriolano, A. T. \& Oliveira, R. A. G. (2007). Use of medicinal plants by patients with cancer of public hospitals in João Pessoa (PB). Revista Espaço para a Saúde, 8(2), 44-52.

Arnous, A. H. Santos, A. S. \& Beinner, R. P. C. (2005). Plantas Medicinais de Uso Caseiro - Conhecimento Popular e Interesse por Cultivo Comunitário. Revista Espaço para a Saúde, 6(2), 1-6.

Balbinot, S. Velasquez, P. G. Düsman, E. (2013). Reconhecimento e uso de plantas medicinais pelos idosos do Município de Marmeleiro - Paraná. Revista Brasileira de Plantas Medicinais, 15(4), 632-38.

Biavatti, M. W. Marensi, V. Leite, S. N. \& Reis, A. (2007). Ethnopharmacognostic survey on botanical compendia for potential cosmeceutic species from Atlantic Forest. Revista Brasileira de Farmacognosia, 17(4), 640-653.

Bisht, A. K. Bhatt, A. Rawal, R. S. \& Dhar, U. (2006). Prioritization and conservation of Himalayan medicinal plants: Angelica glauca Edgew. as a case study. Ethnobotany Research \& Applications, 4, 11-23.

Borba, A. M. \& Macedo, M. (2006). Plantas medicinais usadas para a saúde bucal pela comunidade do bairro Santa Cruz, Chapada dos Guimarães, MT, Brasil. Acta Botânica Brasílica, 20(4), 771-782.

Brasil. Ministério Da Saúde. 2016. Política e Programa Nacional de Plantas Medicinais e Fitoterápicos. Editora MS.

Brito, M. A. \& Coelho, M. F. (2000). Os quintais agroflorestais em regiões tropicais - unidades auto-sustentáveis. Agricultura Tropical, 4(1), 7-35.

Brito, M. F. M. Marin, E. A. \& Cruz, D. D. A. (2017). Plantas medicinais nos assentamentos rurais em uma área de proteção no litoral do Nordeste Brasileiro. Ambiente \& Sociedade, 20(1), 83-104.

Butzke, A. \& Pontalti, S. (2012). Os recursos naturais e o homem: o direito ao meio ambiente ecologicamente equilibrado frente à responsabilidade solidária. 2 ed. Caxias do Sul, RS: Educs, 380p.

Castelluci, S. Lima, M. I. S. Nordi, N. \& Marques, J. G. W. (2000). Plantas medicinais relatadas pela comunidade residente na estação ecológica de Jataí, município de Luis Antônio/SP: uma abordagem etnobotânica. Revista Brasileira de Plantas Medicinais, 3, 51-60.

Centa, M. Negrelle, R. \& Tomazzoni, M. (2006). Fitoterapia popular: a busca instrumental enquanto prática terapêutica. Universidade Federal de Santa Catarina, Florianópolis. Texto Contexto Enfermagem, 115-121. 
Coan, C. M. Matias, T. (2014). A utilização das plantas medicinais pela comunidade indígena de Ventarra Alta-RS. SaBios: Revista de Saúde e Biologia, 9(1), 11-19.

Dhar, U. Rawal, R. S. \& Upreti, J. (2000). Setting priorities for conservation of medicinal plants -a case study in the Indian Himalaya. Biological Conservation, 95, 57-65.

Di Stasi, L. C. (1996). Plantas Medicinais: Arte e Ciência um Guia de Estudo Interdisciplinar. Unesp, 230p.

Duarte, M. C. T. (2006). Atividade antimicrobiana de plantas medicinais e aromáticas utilizadas no Brasil. Revista MultiCiência, 7, 1-16.

Elisabetsky, E. (2000). Etnofarmacologia como ferramenta na busca de substâncias ativas. In: Simões, C.M.O. Schenkel, E.P. Gosmann, G. (eds). Farmacognosia: da planta ao medicamento. Universidades UFRGS / UFSC, p. 87- 99.

Florentino, A. T. N. Araújo, E. L. \& Albuquerque, U. P. (2007). Contribuição de quintais agroflorestais na conservação de plantas da Caatinga, Município de Caruaru, PE, Brasil. Acta Botânica Brasílica, 21(1), 37-47.

Fonseca-Kruel, V. S. \& Peixoto, A. L. (2004). Etnobotânica na Reserva Extrativista Marinha de Arraial do Cabo, RJ, Brasil. Acta Botânica Brasílica, 18(1), $177-190$.

França, I. S. X. Souza, J. A. Baptista, R. S. \& Britto, V. R. S. (2008). Medicina popular: benefícios e malefícios das plantas medicinais. Revista Brasileira de Enfermagem, 61(2), 201-208.

Franco, F. Lamano-Ferreira, A.P.N. \& Lamano-Ferreira, M. (2011). Etnobotânica: aspectos históricos e aplicativos desta ciência. Caderno de Cultura e Ciência, $10(2), 17-23$

Freitas, A. V. L. Coelho, M. F. B. Pereira, Y. B. Freitas Neto, E. C. \& Azevedo, R. A. B. (2015). Diversidade e usos de plantas medicinais nos quintais da comunidade de São João da Várzea em Mossoró, RN. Revista Brasileira de Plantas Medicinais, 17(4), 845-856.

Google Earth-Mapas. <https://maps.google.com.br/>

Hamilton, A. C. Shengji, J. P. Kessy, J. Khan, A. A. Lagos-Witte, S. \& Shinwari, Z. K. (2003). The purposes and teaching of applied ethnobotany. People and Plants Working Paper 11. WWF, Godalming, UK, 72p.

Ibge. Instituto Brasileiro de Geografia e Estatística. Cidades@. Disponível em: <https://cidades.ibge.gov.br/painel/painel.php?codmun=230840> Acesso em: 05 nov 2017.

Ipece. Instituto de Pesquisa e Estratégia Econômica do Ceará. Projeto atlas de divisas municipais georreferenciadas do estado do Ceará. <http://www.ipece.ce.gov.br/estatistica_geografia/limites_municipais/mapas_projeto_atlas/Mapa\%20Miss\%C3\%A3o\%20Velha.pdf>

Ipece. Instituto de Pesquisa e Estratégia Econômica do Ceará. Perfil Básico Municipal, 2016, Missão Velha. <http://www.ipece.ce.gov.br/perfil_basico_municipal/2016/Missao_Velha.pdf>

Jorge, S. S. A. (2009). Plantas medicinais: coletânea de saberes. 81p.

Lameira O. A. \& Pinto, J. E. B. P. (2008). Plantas medicinais: do cultiva, manipulação e uso à recomendação popular. Embrapa, 264p.

Leão, R. B. A. Ferreira, M. R. C. \& Jardim, M. A. G. (2007). Levantamento de plantas de uso terapêutico no município de Santa Bárbara do Pará, Estado do Pará, Brasil. Revista Brasileira de Farmácia, 88(1), 21-25.

Macêdo, D. G. (2013). Bioprospecção, disponibilidade e conservação de plantas medicinais em um encrave de cerrado na Chapada do Araripe, Nordeste do Brasil. Dissertação de Mestrado. 149 f., Universidade Regional do Cariri- URCA, Crato.

Maciel, M. A. M. Pinto, A. C. \& Veiga-Junior, V. F. (2002). Plantas medicinais: a necessidade de estudos multidisciplinares. Química Nova, 25(3), 429-438.

Martins, A. G. Rosário D. L. Barros, M. N. \& Jardim, M. A. G. (2005). Levantamento etnobotânico de plantas medicinais, alimentares e toxicas da Ilha do Combu, Município de Belém, Estado do Pará. Revista Brasileira de Farmacognosia, 86, 21-30.

Melro, J. C., Fonseca, S. A., Silva, J. M., Franco, S. P. B., Souza, M. A., Pimentel, Y. F., \& Santos, A. F. (2019). Ethnodirigid study of Medicinal plants used by the population assisted by the "Programa de Saúde da Família" (Family Health Program) in Marechal Deodoro-AL, Brazil. Brazilian Journal of Biology, 80, $410-423$.

Moraes, M. E. A. \& Santana, G. S. M. (2001). Aroeirado-sertão: um candidato promissor para o tratamento de úlceras gástricas. Fortaleza: Funcap, 3, 5-6.

Morais, V. M. (2011). Etnobotânica nos quintais da comunidade de Abderramant em Caraúbas - RN. Tese de Doutorado. 112 f., Universidade Federal Rural do Semiárido, Mossoró.

Morais, E. F. Plantas medicinais cultivadas em quintais: uma análise etnobotânica. (2015). Revista científica da escola da saúde, 3, 41-50.

Mosca, V. P. \& Loiola, M. I. B. (2009). Uso popular de plantas medicinais no Rio Grande do Norte, nordeste do Brasil. Revista Caatinga, $22,225-234$.

Murrieta, R. S. S. \& Winklerprins, A. M. G. A. (2003). Flowers of water: homegardens and gender roles in a riverine caboclo community in the lower Amazon, Brazil. Culture and Agriculture, 25, 35-47.

Nascimento, A. P. B. (2008). Sobrepeso e obesidade: dieta, uso de recursos e adaptabilidade em populações humanas rural e urbana de Piracicaba, SP. Tese de Doutorado. 96 f., Escola Superior de Agricultura Luiz de Queiroz- ESALQ/USP, Piracicaba. 
Neto, F. R. G. Almeida, G. S. S. A. Jesus, N. G. \& Fonseca, M. R. (2014). Estudo etnobotânico de plantas medicinais utilizadas pela Comunidade do Sisal no município de Catu, Bahia, Brasil. Revista Brasileira de Plantas Medicinais, 16(4), 856-865.

Nordori, R. O. \& Guerra, M. P. (1999). Biodiversidade: aspectos biológicos, geográficos, legais e éticos. In: C. M. O. Simões et al. (ed). Farmacognosia: da planta ao medicamento. Porto Alegre, Editoras UFRGS/ UFSC, 11-24.

Oliveira, G. L. (2007). Etnobotânica Nordestina: plantas medicinais da comunidade Muribeca (Jaboatão dos Guararapes -PE, Brasil). Dissertação de Mestrado. 95 f., Universidade Federal de Pernambuco, Recife.

Penrod, J. Preston, D. B. Cain, R. \& Starks, M. T. (2003). A discussion of chain referral as a method of sampling hard-to-reach populations. Journal of Transcultural nursing, 4(2), 100-107.

Pinto, E. P. P. Amorozo, M. C. \& Furlan, A. (2006). Conhecimento popular sobre plantas medicinais em comunidades rurais de mata atlântica - Itacaré, BA, Brasil. Acta Botânica Brasílica, 20, 751-762.

Pinto, L. N. (2008). Plantas Medicinais Utilizadas em Comunidades do Município de Igarapé - Miri, Pará: Etnofarmácia do Município de Igarapé Miri - PA. Dissertação de Mestrado. 112 f., Universidade Federal do Pará, Instituto de Ciências da Saúde, Belém.

Flora Brasil (2020). Jardim Botânico do Rio de Janeiro (JBRJ) <http://reflora.jbrj.gov.br/reflora/listaBrasil/ConsultaPublicaUC/ResultadoDaConsu ltaNovaConsulta.do\#CondicaoTaxonCP>

Ribeiro, D. A. Macêdo, D. G. Oliveira, L. G. S. Saraiva, M. E. Oliveira, S. F. Souza, M. M. A. \& Menezes, I. R. A. (2014). Potencial terapêutico e uso de plantas medicinais em uma área de Caatinga no estado do Ceará, nordeste do Brasil. Revista Brasileira de Plantas Medicinais, 16(4), 912-930.

Rodrigues, A. P. \& Andrade, L. H. C. (2014). Levantamento etnobotânico das plantas medicinais utilizadas pela comunidade de Inhamã, Pernambuco, Nordeste do Brasil. Revista Brasileira de Plantas Medicinais, 16(3), 721-730.

Rodrigues, F. B. M. Mendonça, C. V. A. \& Mendiola, M. A. (2009). Etnobotânica e desenvolvimento sustentável: recordar o passado para sustentar o futuro. $1^{\circ}$ Congresso de Desenvolvimento Regional de Cabo verde. II Congresso Lusófono de Ciência Regional, 2335 - 2348.

Rodrigues, J. S. C. Figueiredo, A. C. Barroso, J. G. \& Pedro, L. G. (2007). Potencialidades e Aplicações das Plantas Aromáticas e Medicinais: Estudo etnobotânico das plantas aromáticas e medicinais. Curso Teórico-Prático, 168-174.

Salgado, C.L. \& Guido, L.F.E. (2008). O conhecimento popular sobre plantas: um estudo etnobotânico em quintais do distrito de Martinésia, MG. In: IV Encontro da Associação Nacional de Pesquisa e Pós-graduação em Ambiente e Sociedade. Brasília, 2008.

Santos, M. O., Ribeiro, D. A., Macêdo, D. G., Macedo, M. J., Macedo, J. G., Lacerda, M. N. S., \& Maria, A. (2018). Medicinal Plants: versatility and concordance of use in the caatinga area, Northeastern Brazil. Anais da Academia Brasileira de Ciências, 90, 2767-2779.

Santos, M. R. A. \& Lima, M. R. (2009). Levantamento dos recursos vegetais utilizados como fitoterápicos no município de Cujubim, Rondônia, Brasil. Boletim de Pesquisa e Desenvolvimento, 1 ed., Embrapa Rondônia,

Silva, C. G. Marinho, M. G. V. Lucena, M. F. A. \& Costa, J. G. M. (2015). Levantamento etnobotânico de plantas medicinais em área de Caatinga na comunidade do Sítio Nazaré, município de Milagres, Ceará, Brasil. Revista Brasileira de Plantas Medicinais, 17(1), 133-142.

Silva, E. D., Matias, S. M. S., Barros, B. G. A., \& de Oliveira, F. J. V. (2021). A importância do uso das plantas medicinais, frente ao cenário atual da pandemia causada pelo SARS-CoV-2. Research, Society and Development, 10(11), e399101119834-e399101119834.

Silva Junior, A. A. \& Michalak, E. (2014). O Éden de Eva. Florianópolis: Epagri, 227p.

Silva Prim, M. B. (2017). História das Ervas. s.d. Disponível em: <http://users.matrix.com.br/mariabene/breve_historia_das_ervas.htm> Acesso em 23 de julho de 2017.

Silva, S. N. Sousa, F. C. S. Gurjão, K. C. O. \& Siqueira, E. C. (2016). Levantamento de espécies vegetais em área de Caatinga e potencial de uso no Cariri Cearense. I Congresso da Diversidade do Semiárido - CONIDIS, Campina Grande, $11 \mathrm{p}$.

Sousa, N. M. M. Silva, E. S. \& Almeida, F. B. (2016). Uso e diversidade de plantas medicinais da caatinga como recurso terapêutico. I Congresso da Diversidade do Semiárido - CONIDIS, Campina Grande, $10 \mathrm{p}$.

Souza, L. F. Dias, R. F. Guilherme, F. A. G. \& Coelho, C. P. (2016). Plantas medicinais referenciadas por raizeiros no município de Jataí, estado de Goiás. Revista Brasileira de Plantas Medicinais, 18(2), 451-461.

Staniski, A. Floriani, N. \& Strachulski, J. (2014). Estudo etnobotânico de plantas medicinais na comunidade faxinalense Sete Saltos de Baixo, Ponta Grossa PR.Terr@Plural, 8, 321-240.

Veiga J. R. V. F. (2008). Estudo do consumo de plantas medicinais na Região Centro Norte do Estado do Rio de Janeiro. Revista Brasileira de Farmacognosia, $18(2), 308-313$.

Viu, A. F. M. Viu, M. A. O. \& Campos, L. Z. (2010). Etnobotânica: uma questão de gênero?. Revista Brasileira de Agroecologia, 5(1), 138-147 